\title{
Effect of Rainfall Events on SMAP Radiometer-Based Soil Moisture Accuracy Using Core Validation Sites
}

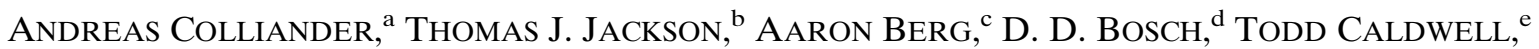 \\ Steven Chan, ${ }^{\mathrm{a}}$ Michael H. Cosh,${ }^{\mathrm{b}}$ C. Holifield Collins, ${ }^{\mathrm{f}}$ Jose Martínez-Fernández, ${ }^{\mathrm{g}}$

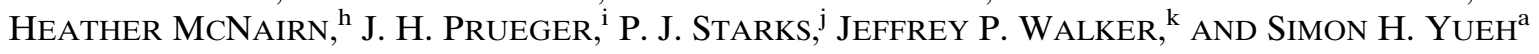 \\ a Jet Propulsion Laboratory, California Institute of Technology, Pasadena, California \\ ${ }^{\mathrm{b}}$ USDA ARS, Hydrology and Remote Sensing Laboratory, Beltsville, Maryland \\ ${ }^{\mathrm{c}}$ University of Guelph, Guelph, Ontario, Canada \\ ${ }^{\mathrm{d}}$ USDA ARS Southeast Watershed Research, Tifton, Georgia \\ ${ }^{\mathrm{e}}$ USGS Nevada Water Science Center, Carson City, Nevada \\ ${ }^{\mathrm{f}}$ USDA ARS Southwest Watershed Research, Tucson, Arizona \\ ${ }^{\mathrm{g}}$ University of Salamanca, Salamanca, Spain \\ ${ }^{\mathrm{h}}$ Agriculture and Agri-Food Canada, Ottawa, Ontario, Canada \\ ${ }^{\mathrm{i}}$ USDA ARS National Laboratory for Agriculture and the Environment, Ames, Iowa \\ ${ }^{\mathrm{j}}$ USDA ARS Grazinglands Research Laboratory, El Reno, Oklahoma \\ ${ }^{\mathrm{k}}$ Monash University, Melbourne, Victoria, Australia
}

(Manuscript received 31 May 2019, in final form 11 December 2019)

\begin{abstract}
Soil moisture retrieval is particularly challenging during and immediately after precipitation events because of the transient movement of water in the shallow subsurface. Conventional L-band microwave radiometerbased soil moisture products use algorithms that assume a static state and a constant vertical soil moisture distribution. This study assessed the retrieval performance of a SMAP radiometer-based soil moisture product during and immediately after rain events. The removal of the rain event samples systematically improved the unbiased root-mean-square error (ubRMSE) from 0.037 (all measurements) to $0.028 \mathrm{~m}^{3} \mathrm{~m}^{-3}$ (transitory measurements screened out), while the magnitude of the bias became larger (from -0.005 to $-0.014 \mathrm{~m}^{3} \mathrm{~m}^{-3}$ ); RMSE improved from 0.047 to $0.042 \mathrm{~m}^{3} \mathrm{~m}^{-3}$, and the Pearson correlation saw a minor positive change from 0.813 to 0.824 . The results indicate that removing samples during the transitional period causes the comparison to improve, but also suggests that the true bias may be larger than the one estimated using all the samples. Furthermore, the results revealed that the effect was stronger for areas with high clay content. An assessment of the performance of the product during the rain events (overpass within $3 \mathrm{~h}$ from the start of the rain) showed that the ubRMSE degraded from the benchmarked $0.036 \mathrm{~m}^{3} \mathrm{~m}^{-3}$ (during no rain events at all) to $0.043 \mathrm{~m}^{3} \mathrm{~m}^{-3}$ (during rain). The results also showed that the bias became wetter, which is expected because SMAP sensed the water on the surface before propagating to the in situ sensors. SMAP maintains its soil moisture sensitivity even during rain events and screening of rain events may not be necessary to ensure sufficient soil moisture retrieval quality.
\end{abstract}

\section{Introduction}

Remotely sensed soil moisture improves the performance of many hydrological applications, ranging from weather forecast and climate modeling to flood prediction and drought mitigation. Precipitation events represent critical time periods with enormous impact on such applications. However, this kind of event creates a

Corresponding author: Andreas Colliander, andreas.colliander@ jpl.nasa.gov vertically uneven distribution of moisture in the top layer of soil. To implement soil moisture retrieval algorithms with low latency on a global basis, it has been necessary to simplify real-world conditions as well as the models used to represent them. One of the common assumptions (or stipulations) has been that the retrieved soil moisture is uniform over a fixed depth (Jackson 1993; Njoku and Entekhabi 1996; Mladenova et al. 2014). In reality, the contributing depth varies with the soil moisture level as well as the distribution over that depth (e.g., Njoku and Kong 1977). One advantage of 
assuming a fixed depth is that it is easier for users to interpret and utilize the resulting data products. Another advantage of the assumption is that this allows the use of the Fresnel equations in the soil moisture retrieval. These assumptions apply reasonably well under most conditions, but are also a source of uncertainty.

When conducting validation of remotely sensed satellite products, it is common practice to use in situ soil moisture sensors (e.g., Jackson et al. 2010, 2012; Peischl et al. 2012; Kerr et al. 2016; Colliander et al. 2017, 2018; Ye et al. 2019, manuscript submitted to Remote Sens. Environ.). Typically, the shallowest depth measured is the 5-cm layer (Adams et al. 2015; Ochsner et al. 2013). In most situations, the probe is inserted horizontally centered at a $5-\mathrm{cm}$ depth and responds primarily to the $3.5-6.5-\mathrm{cm}$ layer, dependent on the physical characteristics of the instrumentation used for the measurement. Some networks install vertically from the surface (Smith et al. 2012) and others measure a layer thicker than $5 \mathrm{~cm}$ (e.g., Merlin et al. 2008; Adams et al. 2015). Therefore, conditions at a slightly deeper depth than the top-down observation of the remote sensor may dominate the in situ measurements.

One of the most obvious situations when there would be a difference between what an in situ sensor and a satellite instrument would observe is during and shortly after a rainfall event before the moisture has equalized within the surface layer. Consequently, the retrieval is expected to indicate a very wet condition while the in situ sensor is likely to observe a drier state. Rondinelli et al. (2015) and Shellito et al. (2016) studied specifically the discrepancy of the drydown rate between in situ measurements and L-band radiometer based soil moisture finding it to be nonnegligible. This discrepancy raises the question of whether the near-rain retrievals should be flagged for caution in usage, and if flagged, should they be removed from the validation dataset. There are also major challenges to flagging these conditions for near-real-time processing. The SMAP radiometer-based soil moisture product contains a flag for rainfall events which is based on modeled precipitation (Chan et al. 2016), but it captures only a fraction of the actual rainfall occurring during satellite overpasses.

This investigation examined two cases: 1) the impact of using observed precipitation to screen out postrain conditions, and 2) the performance of the soil moisture retrieval during rain. The analysis used the radiometer-based soil moisture product from the Soil Moisture Active Passive (SMAP) mission (Entekhabi et al. 2010a). Validation was based on core validation sites (CVS; Colliander et al. 2017) that had precipitation gauges in addition to a dense network of soil moisture sensors.

\section{Datasets}

The analyses used a SMAP radiometer-based soil moisture product and data from select CVS over a period of a little over 3.5 years (1 April 2015-21 December 2018). The subsequent sections describe these data sources.

\section{a. SMAP data}

The SMAP Enhanced Level 2 Soil Moisture Passive (L2SMPE) product was used in this study. Chan et al. (2018) presents the details of the algorithm. The baseline algorithm uses vertically polarized brightness temperature and a single-channel algorithm (SCA-V) (Jackson 1993). The soil moisture retrievals are posted on the SMAP EASE-2 9-km grid while the retrieval domain is $33 \mathrm{~km}$, which closely corresponds to the footprint of the SMAP radiometer (Piepmeier et al. 2017). The brightness temperature processing utilizes the Backus-Gilbert optimal interpolation technique to represent the conically scanned brightness temperature measurements on the 9-km grid (Chaubell et al. 2017). The SCA-V algorithm uses the $\tau-\omega$ model for vegetation modeling and a single parameter roughness correction for predicting brightness temperature. The algorithm uses the GMAO MERRA-2 land surface model to determine the effective soil and vegetation temperatures. The $\tau-\omega$ model implementation uses vegetation water content (VWC) to estimate vegetation opacity; MODIS NDVI climatology provides the basis for the VWC. Finally, the algorithm uses for the roughness correction and vegetation scattering $\omega$ coefficients empirical values obtained in past field experiments (O'Neill et al. 2018).

The analysis used a centered validation grid pixel over each CVS and the 0600 local time SMAP overpasses. The expectation is that the early morning surface and vegetative thermal conditions are more consistent with the isothermal assumptions made in the retrieval algorithm (O'Neill et al. 2018). Therefore, focusing on these overpasses best eliminates potential error sources associated with temperature gradients in soil and between soil and canopy.

\section{b. In situ data}

The analysis utilized the CVS for in situ ground truth. Each CVS includes multiple soil moisture monitoring stations within the product resolution cell (Fig. 1) and satisfies other requirements related to sensor calibration and upscaling reliability (Colliander et al. 2017). Table 1 shows the list of CVS used in the analysis, and Fig. 2 shows the locations. This subset was selected from the full set of CVS (Colliander et al. 2017), based on whether or not the site had reliable rain gauges installed 


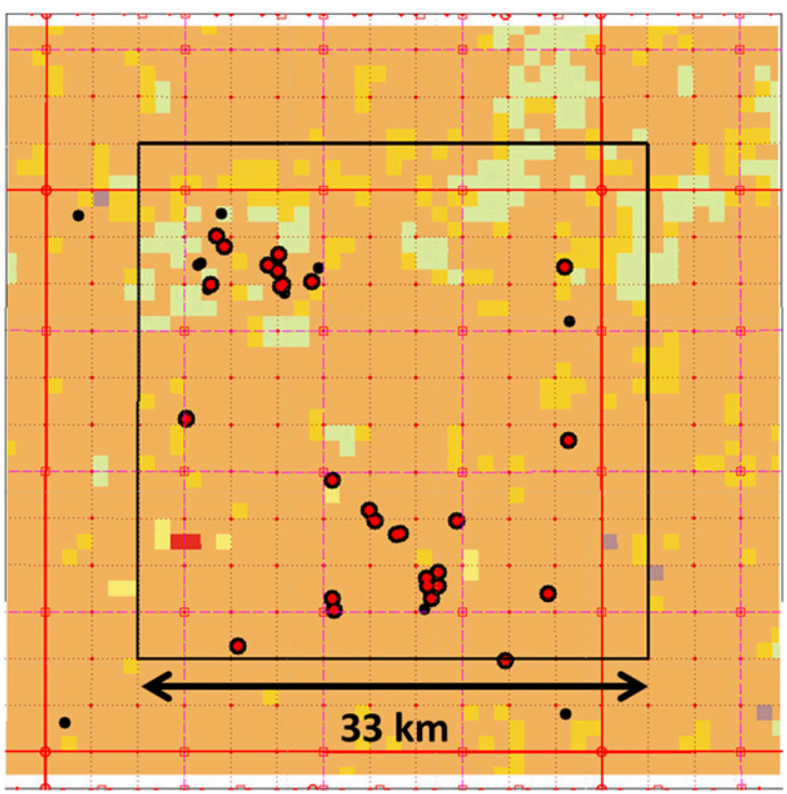

FIG. 1. Layout of the TxSON CVS. The red dots indicate the locations of the stations and the black rectangle the grid area of the SMAP retrieval.

at the location of (most) soil moisture stations. These rain gauges allow reliable estimation of the precipitation activity within the site domain. The soil moisture data were processed and upscaled as described in Colliander et al. (2017). The in situ stations measure a very smallscale sample of soil moisture. The goal of the upscaling process is to use the in situ measurements to estimate the large-scale average soil moisture corresponding to the SMAP footprint. The average of the stations gives a statistical estimate of the mean soil moisture within the pixel. Because the soil moisture has typically relative large spatial variance, a number of stations are needed for establishing a reliable estimate for the mean (e.g., Cosh et al. 2006; Famiglietti et al. 2008; Chen et al. 2019). In most cases, the upscaling process used the Voronoi diagram approach, which prevents clusters of stations from dominating the sampled average. In some cases, the knowledge of the soil texture distribution was used to aid in coming up with the best estimate of the mean soil moisture. The processing also averaged the rain gauge measurements within each site and recorded the occurrence of rain if the hourly rain amount exceeded $0.2 \mathrm{~mm}$.

\section{Methodology}

The analysis used rain gauge measurements at each of the CVS to detect the occurrence of rain events. With these data, soil moisture retrieved within a certain period after a rain event could be either screened out or selected.

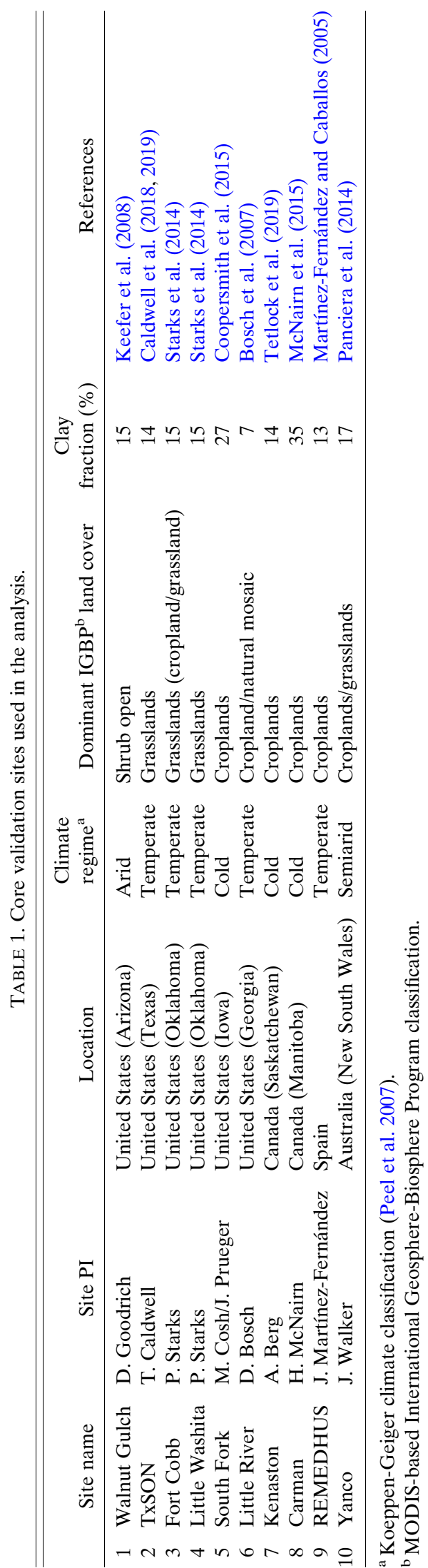




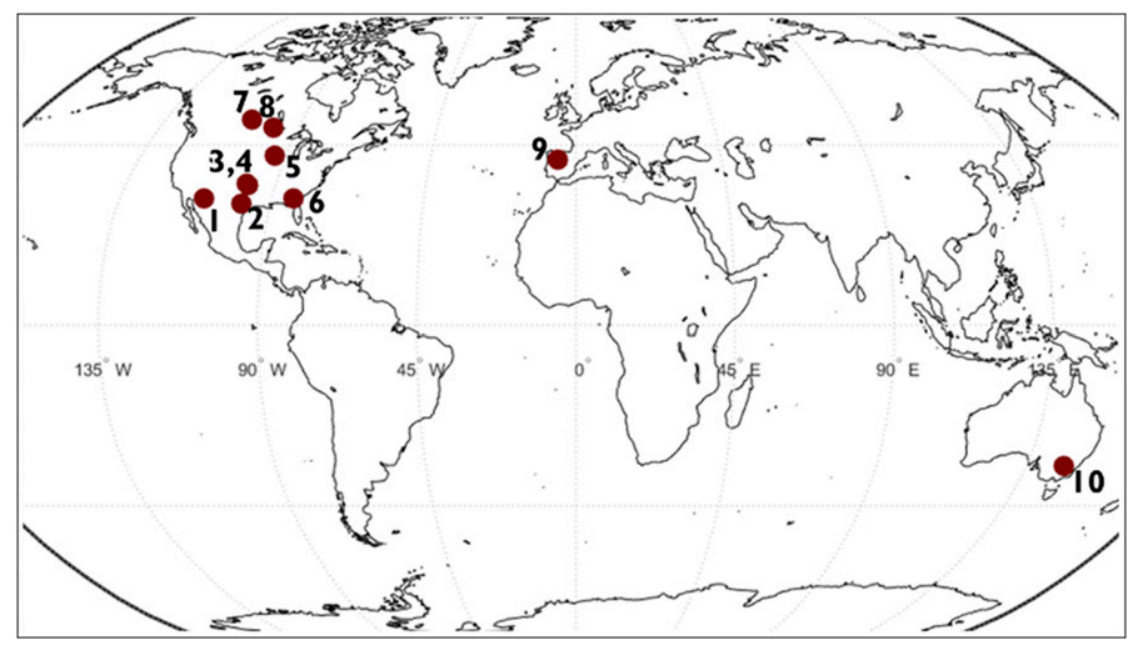

FIG. 2. Locations of the CVS used in the analysis.

The size of the temporal window used in the screening was varied to determine the magnitude of the impact as a function of time (since the rain ceased). The soil moisture retrievals were then compared to the upscaled in situ measurements from the CVS. The performance metrics for five different screen window sizes $(0,3,6,12,24$, and $36 \mathrm{~h})$ were computed. This performance was compared to the case when no screening was applied. The performance metrics included root-mean-square error (RMSE), unbiased RMSE (ubRMSE), Pearson correlation $(R)$, and mean difference (or bias) (Entekhabi et al. 2010b).

The results were further analyzed with respect to the soil texture conditions over the sites. The soil texture has an impact on the infiltration rate. Table 1 lists the estimated clay fraction for each site (average over the
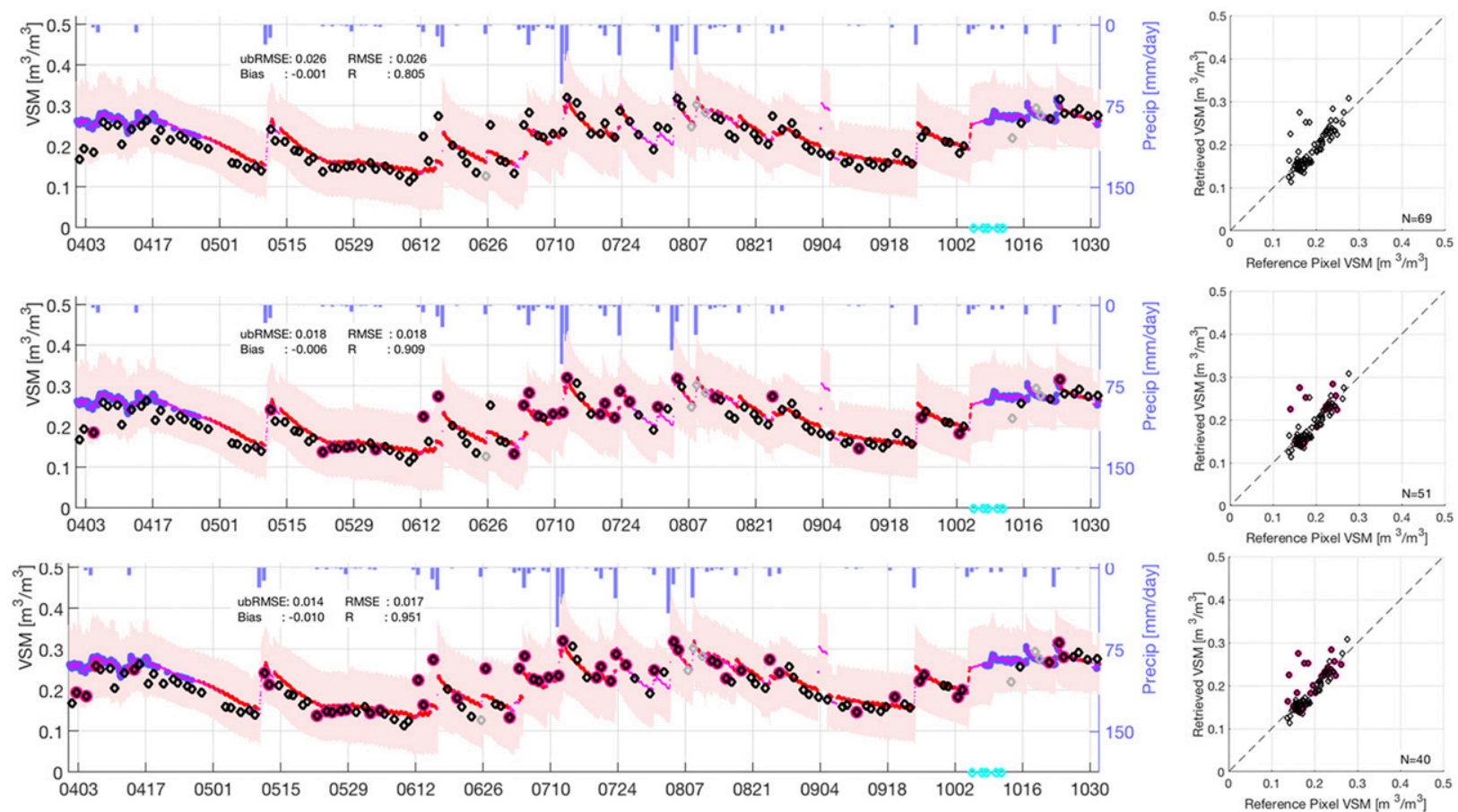

FIG. 3. Sample of rain screening at the Kenaston CVS during the summer of 2016. The red line is the mean CVS in situ soil moisture (the light pink shading indicates the standard deviation of the in situ sensors, and the purple color around the line marks temperatures $<4{ }^{\circ} \mathrm{C}$ ), blue bars indicate the daily precipitation, and black diamonds represent SMAP retrievals. The three rows feature different time windows (no screening, $12 \mathrm{~h}$, and $36 \mathrm{~h}$ ), and the red dots indicate the screened out SMAP retrievals in both time series and scatterplots. 

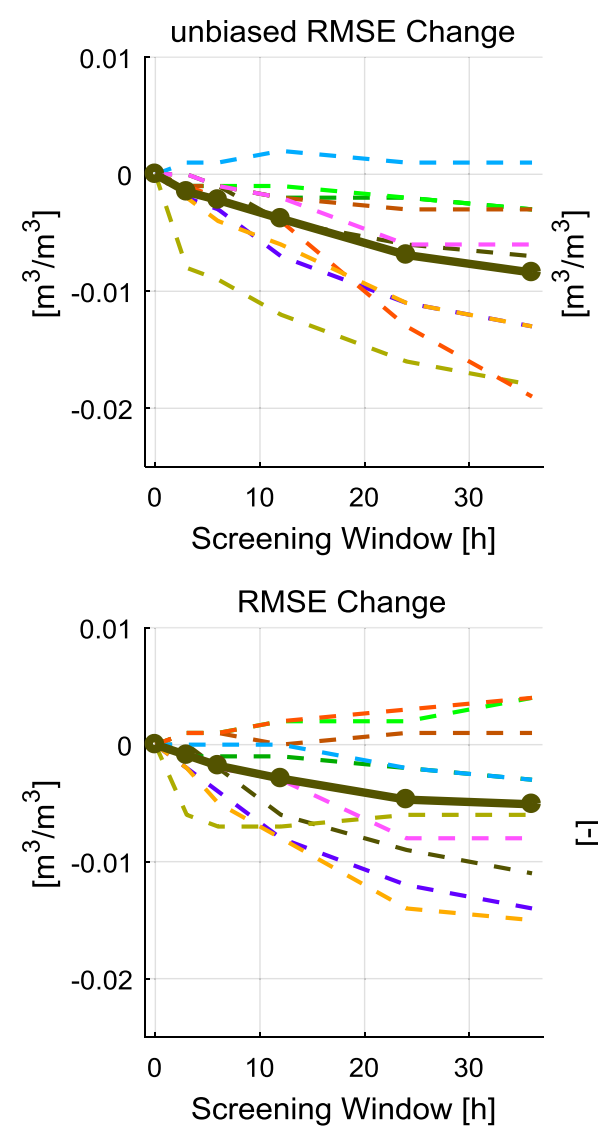
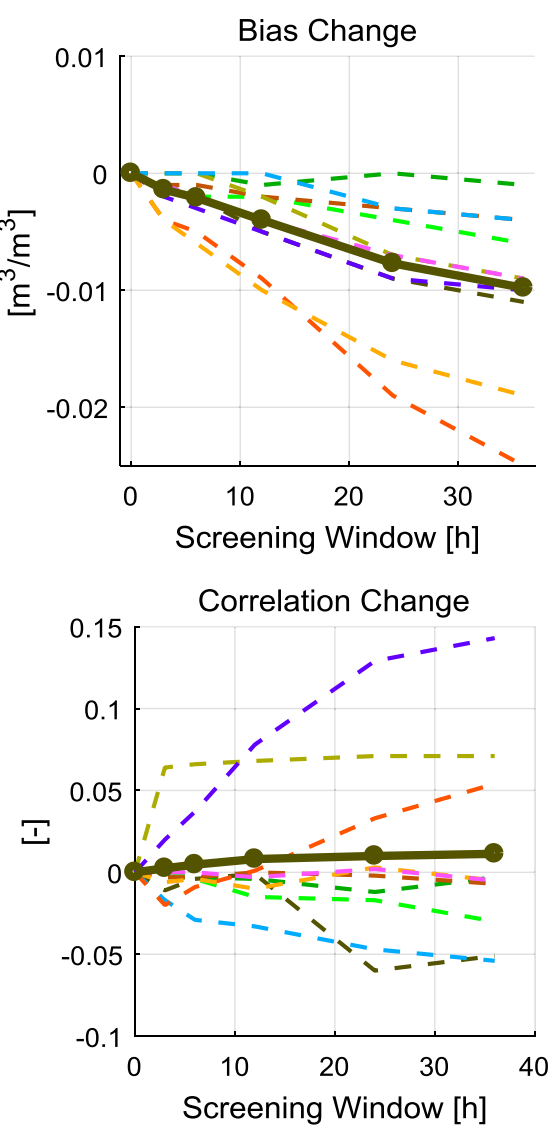
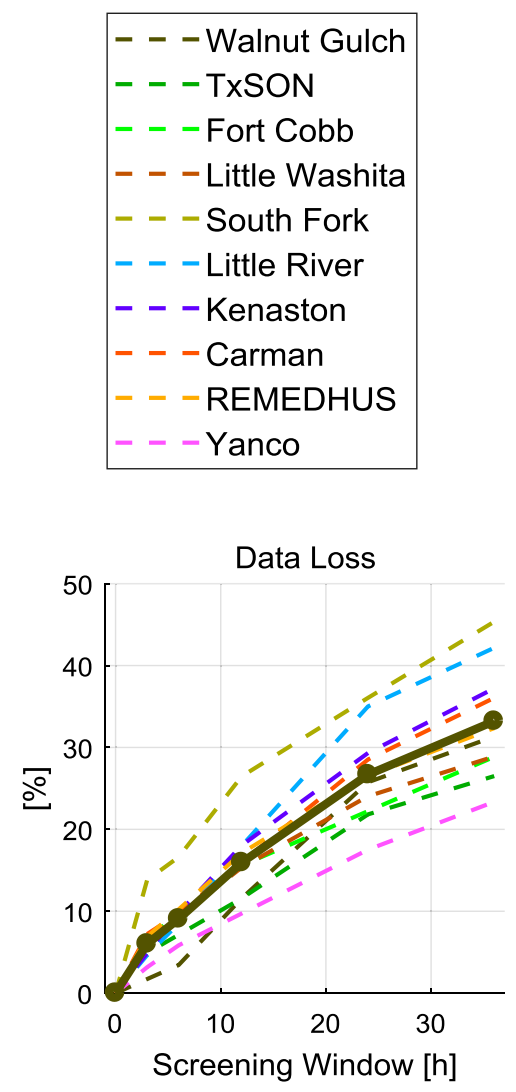

FIG. 4. Change of ubRMSE, bias, RMSE, correlation, and data loss as a function of the screening window. The dashed lines show the values for each site separately and the bold line shows the mean value.

domain). These estimates are based on local soil texture analyses or soil texture databases. The analysis used the change of ubRMSE and bias with a 24-h screening window to investigate their potential relationship to clay fraction. This window size was used because it exhibited robust impact by the screening while still not reducing the number of data points too much.

Similarly, the performance during rain events was estimated. During rain, the emission is attenuated and scattered by the rain droplets causing additional uncertainty on the soil moisture retrievals on top of the effects of the transitioning soil state. The rain attenuation is dependent on the precipitation rate. In general, L-band emission is not assumed to be very sensitive to rain (e.g., Liebe 1989). In this study, we did not try to separate the atmospheric and soil state effects, but focus on the empirical performance of the retrieval based on the in situ measurements of soil moisture. There are only 10-50 soil moisture retrievals that occur within $3 \mathrm{~h}$ of the start of a rain event at any given CVS during the SMAP record; therefore, the analysis compared the performance obtained from these samples to the performance computed from 30 random nonrainy samples at each CVS (rather than all of the nonrainy samples).

TABLE 2. SMAP L2SMPE soil moisture performance metrics for the baseline algorithm (SCA-V) with respect to the core validation sites as a function of the length of the precipitation flagging window.

\begin{tabular}{ccccccrr}
\hline \hline $\begin{array}{c}\text { Screening } \\
\text { window }(\mathrm{h})\end{array}$ & $\begin{array}{c}\text { ubRMSE } \\
\left(\mathrm{m}^{3} \mathrm{~m}^{-3}\right)\end{array}$ & $\begin{array}{c}\text { Bias } \\
\left(\mathrm{m}^{3} \mathrm{~m}^{-3}\right)\end{array}$ & $\begin{array}{c}\text { RMSE } \\
\left(\mathrm{m}^{3} \mathrm{~m}^{-3}\right)\end{array}$ & $\begin{array}{c}R \\
(-)\end{array}$ & $\begin{array}{c}\text { ubRMSE } \\
\text { change }\left(\mathrm{m}^{3} \mathrm{~m}^{-3}\right)\end{array}$ & $\begin{array}{c}\text { Bias } \\
\text { change }\left(\mathrm{m}^{3} \mathrm{~m}^{-3}\right)\end{array}$ & $\begin{array}{c}\text { Data } \\
\text { discarded }(\%)\end{array}$ \\
\hline No screening & 0.037 & -0.005 & 0.047 & 0.813 & 0 & 0 & 0 \\
3 & 0.035 & -0.006 & 0.046 & 0.815 & $-0.002(-5 \%)$ & -0.001 & 6 \\
6 & 0.034 & -0.007 & 0.046 & 0.818 & $-0.003(-8 \%)$ & -0.002 & -0.004 \\
12 & 0.033 & -0.009 & 0.045 & 0.821 & $-0.004(-11 \%)$ & -0.007 & 27 \\
24 & 0.03 & -0.012 & 0.043 & 0.823 & $-0.007(-19 \%)$ & -0.009 & 33 \\
36 & 0.028 & -0.014 & 0.042 & 0.824 & $-0.009(-24 \%)$ & & 0 \\
\hline
\end{tabular}



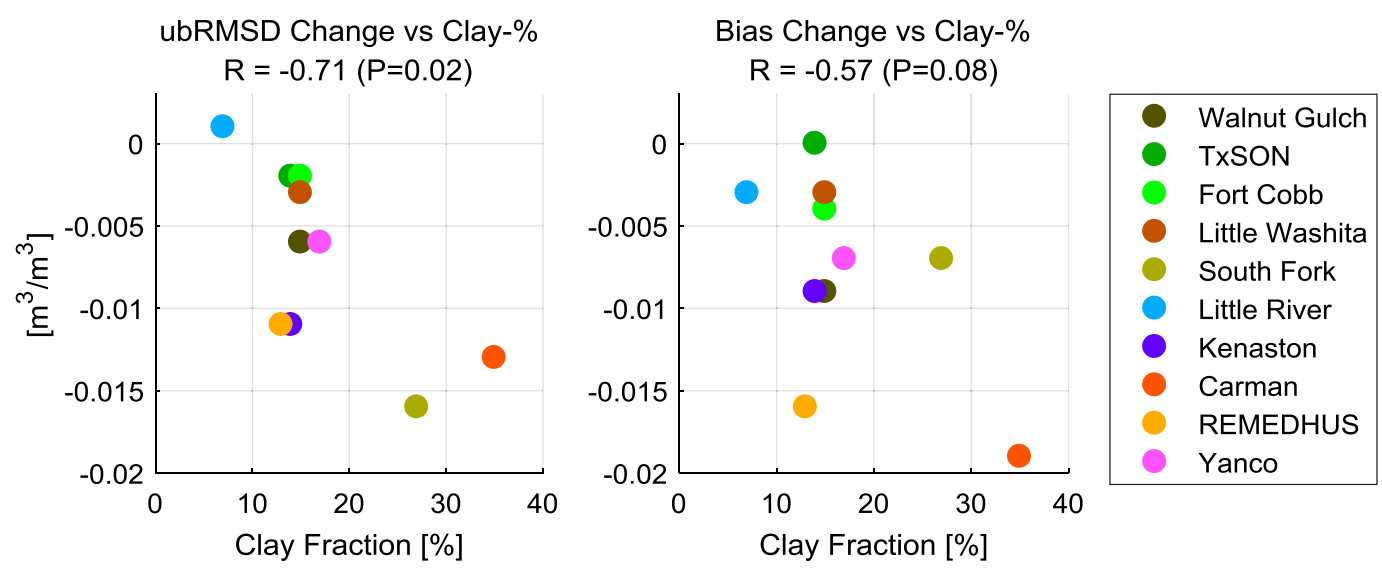

FIG. 5. The change of soil moisture ubRMSD and bias with 24-h screening window as a function of the clay fraction at each site; $R$ stands for the Pearson correlation and $P$ for the $p$ value.

The SMAP product includes a precipitation flag based on the GMAO Goddard Earth Observing System (GEOS) model precipitation fields (Chan et al. 2016). However, because the flag captures only a fraction of the actual precipitation events over the CVS, it has a negligible influence on the performance metrics. The number of measurements flagged with the precipitation flag were less than half of the number of measurements flagged with the 3 -h window. Therefore, we did not address the event-based skill of the SMAP flagging protocol, as it would not make any difference in this analysis.

\section{Results}

\section{a. Effect of postrain screening on SMAP performance}

Figure 3 shows a sample screening of postrain retrievals for the Kenaston CVS during the summer of 2016. The plots feature no screening, a 12-h screening window, and a $36-\mathrm{h}$ window. The time series and the scatterplot show the screened out retrievals with red dots. The ubRMSE decreased with longer windows while the absolute value (magnitude) of the bias became larger; overall, the RMSE improved. The results also show the obvious consequence of a reduced number of retrievals with screening. With a $36-\mathrm{h}$ window over $40 \%$ of the retrievals are lost for this site during the period. On one hand, the performance improved, but on the other hand, data are discarded. The improvement in the performance is a result of removing observations during transitory soil moisture profiles, but also a result of removing comparatively wetter samples from the soil moisture distribution.

The results showed that the mean ubRMSE of the in situ comparisons improved with increasing time window size. With a 36-h window the improvement reached $22 \%$ (reducing ubRMSE from 0.037 to $0.028 \mathrm{~m}^{3} \mathrm{~m}^{-3}$ ), but at the same time about a third of the data were discarded and the mean bias increased from -0.005 to $-0.014 \mathrm{~m}^{3} \mathrm{~m}^{-3}$ (Fig. 4 and Table 2). The only site where ubRMSE did not decrease as the result of screening was Little River. The Carman site has soil moisture sensors installed horizontally and vertically at the same locations. This analysis used the horizontally installed sensors to be consistent with most of the other sites. However, for the vertically installed sensors the impact of the screening was not as clear. It is possible that the vertically installed sensors correspond better to the measurement of microwave remote sensing, which is also a top-down measurement (Adams et al. 2015).

TABLE 3. SMAP L2SMPE soil moisture performance metrics for the optional SCA-H with respect to the core validation sites as a function of the length of the precipitation flagging window.

\begin{tabular}{|c|c|c|c|c|c|c|c|}
\hline $\begin{array}{l}\text { Screening } \\
\text { window }(\mathrm{h})\end{array}$ & $\begin{array}{l}\text { ubRMSE } \\
\left(\mathrm{m}^{3} \mathrm{~m}^{-3}\right)\end{array}$ & $\begin{array}{c}\text { Bias } \\
\left(\mathrm{m}^{3} \mathrm{~m}^{-3}\right)\end{array}$ & $\begin{array}{c}\mathrm{RMSE} \\
\left(\mathrm{m}^{3} \mathrm{~m}^{-3}\right)\end{array}$ & $\begin{array}{l}R \\
(-)\end{array}$ & $\begin{array}{c}\text { ubRMSE } \\
\text { change }\left(\mathrm{m}^{3} \mathrm{~m}^{-3}\right)\end{array}$ & $\begin{array}{c}\text { Bias } \\
\text { change }\left(\mathrm{m}^{3} \mathrm{~m}^{-3}\right)\end{array}$ & $\begin{array}{c}\text { Data } \\
\text { discarded (\%) }\end{array}$ \\
\hline No screening & 0.043 & -0.039 & 0.064 & 0.784 & & & 0 \\
\hline 3 & 0.042 & -0.04 & 0.063 & 0.784 & -0.001 & -0.001 & 6 \\
\hline 6 & 0.041 & -0.04 & 0.063 & 0.788 & -0.002 & -0.001 & 9 \\
\hline 12 & 0.039 & -0.042 & 0.063 & 0.792 & -0.004 & -0.003 & 16 \\
\hline 24 & 0.036 & -0.046 & 0.063 & 0.789 & -0.007 & -0.007 & 27 \\
\hline 36 & 0.034 & -0.049 & 0.064 & 0.795 & -0.009 & -0.01 & 33 \\
\hline
\end{tabular}


TABLE 4. SMAP L2SMPE soil moisture performance metrics for the optional DCA with respect to the core validation sites as a function of the length of the precipitation flagging window.

\begin{tabular}{cccccccc}
\hline \hline $\begin{array}{c}\text { Screening } \\
\text { window }(\mathrm{h})\end{array}$ & $\begin{array}{c}\text { ubRMSE } \\
\left(\mathrm{m}^{3} \mathrm{~m}^{-3}\right)\end{array}$ & $\begin{array}{c}\text { Bias } \\
\left(\mathrm{m}^{3} \mathrm{~m}^{-3}\right)\end{array}$ & $\begin{array}{c}\text { RMSE } \\
\left(\mathrm{m}^{3} \mathrm{~m}^{-3}\right)\end{array}$ & $\begin{array}{c}R \\
(-)\end{array}$ & $\begin{array}{c}\text { ubRMSE } \\
\text { change }\left(\mathrm{m}^{3} \mathrm{~m}^{-3}\right)\end{array}$ & $\begin{array}{c}\text { Bias } \\
\text { change }\left(\mathrm{m}^{3} \mathrm{~m}^{-3}\right)\end{array}$ & $\begin{array}{c}\text { Data } \\
\text { discarded }(\%)\end{array}$ \\
\hline No screening & 0.048 & 0.044 & 0.076 & 0.74 & & & 0 \\
3 & 0.046 & 0.042 & 0.074 & 0.733 & -0.002 & -0.002 & 6 \\
6 & 0.046 & 0.041 & 0.073 & 0.733 & -0.002 & -0.003 & 16 \\
12 & 0.044 & 0.038 & 0.07 & 0.731 & -0.004 & -0.006 & 27 \\
24 & 0.041 & 0.034 & 0.066 & 0.725 & -0.007 & -0.01 & 33 \\
36 & 0.041 & 0.033 & 0.065 & 0.721 & -0.007 & & 3 \\
\hline
\end{tabular}

However, the sensors are installed vertically also at Yanco, which performs very close to the mean of all sites. As the absolute value of bias increased for all sites, the RMSE value also increased for some sites while decreasing for others depending on the relative magnitudes in bias and ubRMSE change. However, overall the average value of RMSE decreased with screening window length. The average improvement in $R$ was small with high variation from site to site.

Figure 5 shows the comparison of the ubRMSE and bias change with the clay fractions of the sites. The plots show the Pearson correlation $(R)$ and the $p$ value $(P)$ in the title. The results indicate significant correlation between clay fractions and both ubRMSE and bias change. This means that the soils with high clay content made the transitory state more significant and longer than in those with lower clay content (i.e., faster redistribution of moisture due to larger hydraulic conductivity in soils with lower clay content).

The SMAP soil moisture product typically overestimated the $0-5-\mathrm{cm}$ soil moisture during and right after the rain events because of increased water content in the top layer of the soil. Therefore, removing these points is expected to reveal the correct magnitude of the underlying underestimation of the $0-5-\mathrm{cm}$ soil moisture. The results are shown for the SMAP baseline soil moisture retrieval (SCA-V). Tables 3 and 4 show that the results were consistently similar for the other algorithm options [single-channel algorithm using horizontal polarization (SCA-H) and dual-channel algorithm (DCA)].

\section{b. SMAP performance during rain}

Figure 6 shows a comparison between the SMAP retrievals obtained within three hours of a rain event and the in situ soil moisture of the CVS. Table 5 shows the metrics computed using retrievals when there was no rain for each CVS. The retrieval performance degraded during rain but remained reasonable (ubRMSE reduced from 0.043 to $0.036 \mathrm{~m}^{3} \mathrm{~m}^{-3}$ ).

This result indicates that the sensitivity of SMAP to soil moisture is largely maintained during rain events; depending on the accuracy requirements of an application, screening of rain events may not be necessary to ensure sufficient quality of the SMAP retrievals. However, for some applications, even the modest

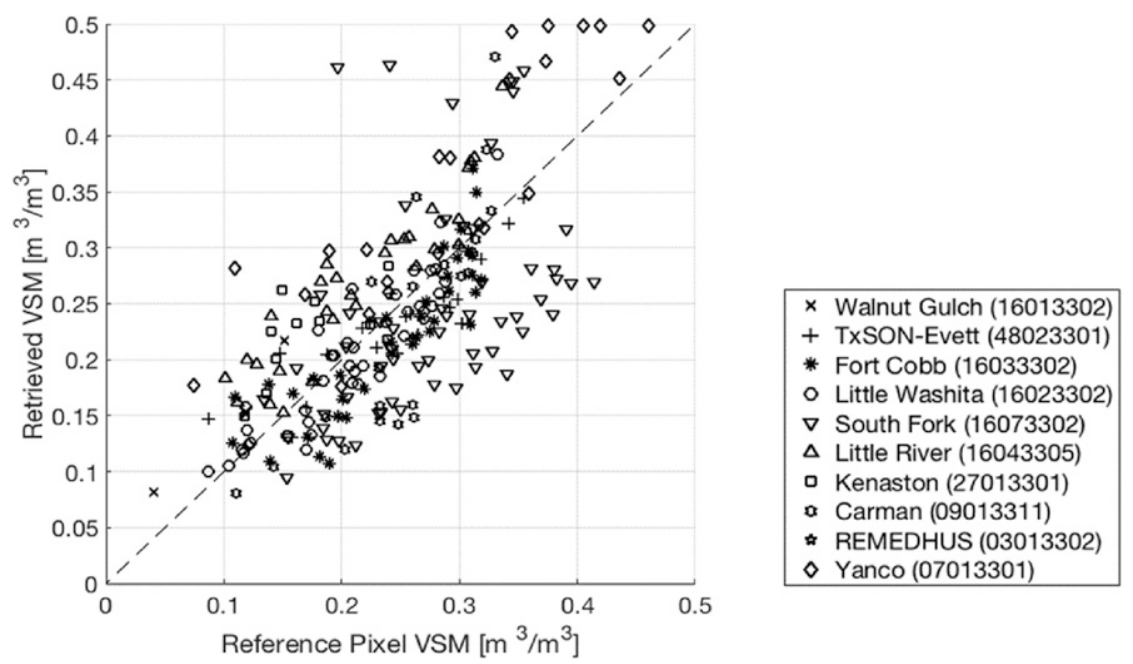

FIG. 6. Scatterplot of the SMAP baseline soil moisture retrievals during rain (within three hours) with respect to the upscaled CVS soil moisture. 
TABLE 5. Performance of the SMAP L2SMPE retrievals during rain and in the absence of rain.

\begin{tabular}{|c|c|c|c|c|c|c|c|c|}
\hline Site name & $\begin{array}{l}\text { ubRMSE } \\
\text { only rain } \\
\left(\mathrm{m}^{3} \mathrm{~m}^{-3}\right)\end{array}$ & $\begin{array}{l}\text { ubRMSE } \\
\text { no rain } \\
\left(\mathrm{m}^{3} \mathrm{~m}^{-3}\right)\end{array}$ & $\begin{array}{l}\text { Bias only rain } \\
\qquad\left(\mathrm{m}^{3} \mathrm{~m}^{-3}\right)\end{array}$ & $\begin{array}{l}\text { Bias no rain } \\
\left(\mathrm{m}^{3} \mathrm{~m}^{-3}\right)\end{array}$ & $\begin{array}{l}\text { RMSE only rain } \\
\qquad\left(\mathrm{m}^{3} \mathrm{~m}^{-3}\right)\end{array}$ & $\begin{array}{l}\text { RMSE no rain } \\
\qquad\left(\mathrm{m}^{3} \mathrm{~m}^{-3}\right)\end{array}$ & $\begin{array}{l}R \text { only rain } \\
(-)\end{array}$ & $\begin{array}{l}R \text { no rain } \\
(-)\end{array}$ \\
\hline Walnut Gulch & 0.013 & 0.022 & 0.044 & 0.018 & 0.046 & 0.029 & 0.97 & 0.688 \\
\hline TxSON & 0.031 & 0.015 & -0.012 & -0.018 & 0.034 & 0.024 & 0.88 & 0.973 \\
\hline Fort Cobb & 0.035 & 0.023 & -0.021 & -0.030 & 0.040 & 0.038 & 0.861 & 0.965 \\
\hline Little Washita & 0.026 & 0.023 & -0.005 & 0.004 & 0.026 & 0.023 & 0.918 & 0.968 \\
\hline South Fork & 0.087 & 0.075 & -0.034 & -0.058 & 0.093 & 0.095 & 0.451 & 0.366 \\
\hline Little River & 0.028 & 0.024 & 0.054 & 0.066 & 0.061 & 0.070 & 0.921 & 0.927 \\
\hline Kenaston & 0.035 & 0.025 & 0.050 & 0.014 & 0.061 & 0.028 & 0.599 & 0.466 \\
\hline Carman & 0.082 & 0.069 & -0.010 & -0.026 & 0.082 & 0.074 & 0.809 & 0.801 \\
\hline Yanco & 0.053 & 0.051 & 0.062 & 0.038 & 0.082 & 0.064 & 0.883 & 0.863 \\
\hline Mean & 0.043 & 0.036 & 0.014 & 0.001 & 0.058 & 0.049 & 0.810 & 0.780 \\
\hline
\end{tabular}

degradation may be significant and ancillary data sources could be applied to flag out the retrievals to maximize the SMAP soil moisture retrieval quality.

\section{Discussion}

The measurement of soil moisture during and after rain events is a critical component in capturing the evolution of soil moisture. To test what is the impact of these transitory periods to the SMAP soil moisture measurement, two different cases were analyzed: in one, the transitory periods were excluded from a variable size time window after a precipitation event, and in another, the SMAP performance during rain was compared to that in clear conditions. The results indicated that the two analyses were complementary. On one hand, the data exclusion exercise showed the improvement in the SMAP, but on the other hand, the performance estimation during rain events showed that these observations are not completely degraded either and significant amount of skill remains. Overall, this result is important when assessing the suitability of the SMAP soil moisture products for different applications.

The results of the data exclusion exercise implied that removing samples measured when the soil moisture profile is transient in $0-5 \mathrm{~cm}$ improves the ubRMSE, because the microwave remote sensing and the soil moisture sensors are not measuring the same layers of the soil. However, the removal of predominantly wetter samples (right after rain) also has the statistical impact of decreasing ubRMSE and increasing bias. The results suggest that the removal of the samples of transitory soil may reveal the true bias in the product. The impact of the transitory soil state was largest over areas with higher clay fraction suggesting that any attempt to improve the retrieval accuracy should be targeted to these areas. The result was mixed for the correlation coefficient $(R)$ : most of the sites experienced slight decrease in
$R$, while it increased for the others making the mean $R$ marginally improving with a longer screening window. Overall, the result is not conclusive how $R$ tends change as a function of the screening. The longest screening window applied was $36 \mathrm{~h}$, and the average data reduction for this window length was about one-third. This resulted in the best performance, but losing one-third of the data is not very appealing prospect for many applications. Therefore, considering flagging scenarios and achievable performance is more relevant for the smaller than 24-h windows, which achieved a maximum performance of about $0.030 \mathrm{~m}^{3} \mathrm{~m}^{-3}$ ubRMSE in this study.

Several studies have successfully relied on nearprecipitation satellite data for various purposes in the past (Pellarin et al. 2008; Crow et al. 2011; Brocca et al. 2013). The presented analysis increases the confidence significantly that L-band radiometer measurements have the fidelity to resolve the soil moisture during rain and in the highly transitory conditions, albeit with somewhat reduced skill. Conceivably, further efforts could reduce these uncertainties.

\section{Conclusions}

This study investigated the impact of rainfall events on the SMAP radiometer-based soil moisture using core validation sites (CVS) that included precipitation gauges. The gauge measurements were used to detect rain for the SMAP observations that occurred during or after rain. The goal was to determine the effect of screening the retrievals that occurred during a certain period after the start of a rain event. The impact was evaluated as a function of the length of the screening window. The unbiased RMSE (ubRMSE) of the SMAP soil moisture product improved as a result of the screening and the impact grew larger with longer windows (from 0.036 to $0.028 \mathrm{~m}^{3} \mathrm{~m}^{-3}$ ). However, the absolute bias increased (from -0.005 to $-20.014 \mathrm{~m}^{3} \mathrm{~m}^{-3}$ ). The impact 
on the Pearson correlation varied from site to site significantly while the change of the overall mean was slightly positive (from 0.813 to 0.824 ).

The study also looked into the performance of the soil moisture product during rain (within three hours after the start of an event). This analysis showed a systematic degradation in the ubRMSE. The ubRMSE during rain was $0.043 \mathrm{~m}^{3} \mathrm{~m}^{-3}$ while it was $0.036 \mathrm{~m}^{3} \mathrm{~m}^{-3}$ during clear periods. The result indicates that the sensitivity of SMAP to soil moisture is largely maintained during rain events; depending on the accuracy requirements of an application, screening of rain events may not be necessary to ensure sufficient quality of the SMAP retrievals.

Acknowledgments. The research described in this publication was carried out in part at the Jet Propulsion Laboratory, California Institute of Technology, under a contract with the National Aeronautics and Space Administration. TxSON receives financial support from the G. Rollie White Foundation and the Dixon Water Foundation. USDA is an equal opportunity employer and provider. The University of Salamanca team involvement in this study was supported by the Spanish Ministry of Science, Innovation and Universities with the project ESP2017-89463-C3-3-R, and the European Regional Development Fund (ERDF). Erica Tetlock from Environment and Climate Change Canada and Jaison Ambadan Thomas are acknowledged for work with the Kenaston Network data with funding from Environment and Climate Change Canada, the Canadian Space Agency, and the Natural Sciences and Engineering Research Council of Canada.

\section{REFERENCES}

Adams, J. R., H. McNairn, A. A. Berg, and C. Champagne, 2015: Evaluation of near-surface soil moisture data from an AAFC monitoring network in Manitoba, Canada: Implications for L-band satellite validation. J. Hydrol., 521, 582-592, https:// doi.org/10.1016/j.jhydrol.2014.10.024.

Bosch, D. D., J. M. Sheridan, R. R. Lowrance, R. K. Hubbard, T. C. Strickland, G. W. Feyereisen, and D. G. Sullivan, 2007: Little River experimental watershed database. Water Resour. Res., 43, W09472, https://doi.org/10.1029/2006WR005844.

Brocca, L., T. Moramarco, F. Melone, and W. Wagner, 2013: A new method for rainfall estimation through soil moisture observations. Geophys. Res. Lett., 40, 853-858, https://doi.org/ 10.1002/grl.50173.

Caldwell, T. G., T. Bongiovanni, M. H. Cosh, C. Halley, and M. H. Young, 2018: Field and laboratory evaluation of the CS655 soil water content sensor. Vadose Zone J., 17, 170214, https:// doi.org/10.2136/vzj2017.12.0214.

- and Coauthors, 2019: The Texas soil observation network: A comprehensive soil moisture dataset for remote sensing and land surface model validation. Vadose Zone J., 18, 100034, https://doi.org/10.2136/vzj2019.04.0034.
Chan, S. K., and Coauthors, 2016: Assessment of the SMAP passive soil moisture product. IEEE Trans. Geosci. Remote Sens., 54, 4994-5007, https://doi.org/10.1109/TGRS.2016.2561938.

— , and Coauthors, 2018: Development and assessment of the SMAP enhanced passive soil moisture product. Remote Sens. Environ., 204, 931-941, https://doi.org/10.1016/j.rse.2017.08.025.

Chaubell, J. M., S. Chan, R. Dunbar, D. Entekhabi, J. Peng, J. Piepmeier, and S. Yueh, 2017: Backus-Gilbert optimal interpoaltion applied to enhance smap data: Implementation and assessment. IEEE Int. Geosci. Remote Sens. Symp., Fort Worth, TX, IEEE, 2531-2534, https://doi.org/10.1109/ IGARSS.2017.8127510.

Chen, F., and Coauthors, 2019: Uncertainty of reference pixel soil moisture averages sampled at SMAP core validation sites. J. Hydrometeor., 20, 1553-1569, https://doi.org/10.1175/ JHM-D-19-0049.1.

Colliander, A., and Coauthors, 2017: Validation of SMAP surface soil moisture products with core validation sites. Remote Sens. Environ., 191, 215-231, https://doi.org/10.1016/ j.rse.2017.01.021.

_ , and Coauthors, 2018: An assessment of the differences between spatial resolution and grid size for the SMAP enhanced soil moisture product over homogeneous sites. Remote Sens. Environ., 207, 65-70, https://doi.org/10.1016/j.rse.2018.02.006.

Coopersmith, E. J., M. Cosh, W. A. Petersen, J. Prueger, and J. J. Niemeier, 2015: Soil moisture model calibration and validation: An ARS watershed on the South Fork Iowa River. J. Hydrometeor., 16, 1087-1101, https://doi.org/10.1175/ JHM-D-14-0145.1.

Cosh, M. H., T. J. Jackson, P. J. Starks, and G. C. Heathman, 2006: Temporal stability of surface soil moisture in the Little Washita River watershed and its applications in satellite soil moisture product validation. J. Hydrol., 323, 168-177, https:// doi.org/10.1016/j.jhydrol.2005.08.020.

Crow, W. T., M. J. van den Berg, G. J. Huffman, and T. Pellarin, 2011: Correcting rainfall using satellite-based surface soil moisture retrievals: The Soil Moisture Analysis Rainfall Tool (SMART). Water Resour. Res., 47, W08521, https://doi.org/ 10.1029/2011WR010576.

Entekhabi, D., and Coauthors, 2010a: The Soil Moisture Active Passive (SMAP) mission. Proc. IEEE, 98, 704-716, https:// doi.org/10.1109/JPROC.2010.2043918.

— R. H. Reichle, R. D. Koster, and W. T. Crow, 2010b: Performance metrics for soil moisture retrievals and application requirements. J. Hydrometeor., 11, 832-840, https:// doi.org/10.1175/2010JHM1223.1.

Famiglietti, J. S., D. Ryu, A. A. Berg, M. Rodell, and T. J. Jackson, 2008: Field observations of soil moisture variability across scales. Water Resour. Res., 44, W01423, https://doi.org/10.1029/ 2006WR005804.

Jackson, T. J., 1993: Measuring surface soil moisture using passive microwave remote sensing. Hydrol. Processes, 7, 139-152, https://doi.org/10.1002/hyp.3360070205.

— , and Coauthors, 2010: Validation of advanced microwave scanning radiometer soil moisture products. IEEE Trans. Geosci. Remote Sens., 48, 4256-4272, https://doi.org/10.1109/ TGRS.2010.2051035.

, and Coauthors, 2012: Validation of Soil Moisture and Ocean Salinity (SMOS) soil moisture over watershed networks in the U.S. IEEE Trans. Geosci. Remote Sens., 50, 1530-1543, https:// doi.org/10.1109/TGRS.2011.2168533.

Keefer, T. O., M. S. Moran, and G. B. Paige, 2008: Long-term meteorological and soil hydrology database, Walnut Gulch 
experimental watershed, Arizona, United States. Water Resour. Res., 44, W05S07, https://doi.org/10.1029/2006WR005702.

Kerr, Y. H., and Coauthors, 2016: Overview of SMOS performance in terms of global soil moisture monitoring after six years in operation. Remote Sens. Environ., 180, 40-63, https://doi.org/ 10.1016/j.rse.2016.02.042.

Liebe, H. J., 1989: MPM-An atmospheric millimeter-wave propagation model. Int. J. Infrared Millimeter Waves, $\mathbf{1 0}$, 631-650, https://doi.org/10.1007/BF01009565.

Martínez-Fernández, J., and A. Ceballos, 2005: Mean soil moisture estimation using temporal stability analysis. J. Hydrol., 312, 28-38, https://doi.org/10.1016/j.jhydrol.2005.02.007.

McNairn, H., and Coauthors, 2015: The Soil Moisture Active Passive Validation Experiment 2012 (SMAPVEX12): Prelaunch calibration and validation of the SMAP soil moisture algorithms. IEEE Trans. Geosci. Remote Sens., 53, 2784-2801, https://doi.org/10.1109/TGRS.2014.2364913.

Merlin, O., and Coauthors, 2008: The NAFE'06 data set: Towards soil moisture retrieval at intermediate resolution. Adv. Water Resour., 31, 1444-1455, https://doi.org/10.1016/ j.advwatres.2008.01.018.

Mladenova, I. E., and Coauthors, 2014: Remote monitoring of soil moisture using passive microwave-based techniquesTheoretical basis and overview of selected algorithms for AMSR-E. Remote Sens. Environ., 144, 197-213, https:// doi.org/10.1016/j.rse.2014.01.013.

Njoku, E. G., and J.-A. Kong, 1977: Theory for passive microwave remote sensing of near-surface soil moisture. J. Geophys. Res., 82, 3108-3118, https://doi.org/10.1029/JB082i020p03108.

, and D. Entekhabi, 1996: Passive microwave remote sensing of soil moisture. J. Hydrol., 184, 101-129, https://doi.org/ 10.1016/0022-1694(95)02970-2.

Ochsner, T. E., and Coauthors, 2013: State of the art in large-scale soil moisture monitoring. Soil. Sci. Soc. Amer. J., 77, 18881919, https://doi.org/10.2136/sssaj2013.03.0093.

O’Neill, P., R. Bindlish, S. Chan, E. G. Njoku, and T. J. Jackson, 2018: Algorithm theoretical basis document level 2 \& 3 soil moisture (passive) data products, revision D. Jet Propulsion Laboratory Rep. JPL D-66480, 82 pp., https:// smap.jpl.nasa.gov/system/internal_resources/details/original/ 484_L2_SM_P_ATBD_rev_D_Jun2018.pdf.
Panciera, R., and Coauthors, 2014: The Soil Moisture Active Passive Experiments (SMAPEx): Toward soil moisture retrieval from the SMAP mission. IEEE Trans. Geosci. Remote Sens., 52, 490-507, https://doi.org/10.1109/TGRS.2013.2241774.

Peel, M. C., B. L. Finlayson, and T. A. McMahon, 2007: Updated world map of the Koeppen-Geiger climate classification. Hydrol. Earth Syst. Sci., 11, 1633-1644, https://doi.org/10.5194/ hess-11-1633-2007.

Peischl, S., J. P. Walker, C. Rüdiger, N. Ye, Y. H. Kerr, E. Kim, R. Bandara, and M. Allahmoradi, 2012: The AACES field experiments: SMOS calibration and validation across the Murrumbidgee River catchment. Hydrol. Earth Syst. Sci., 16, 1697-1708, https://doi.org/10.5194/hess-16-1697-2012.

Pellarin, T., A. Ali, F. Chopin, I. Jobard, and J.-C. Bergès 2008: Using spaceborne surface soil moisture to constrain satellite precipitation estimates over West Africa. Geoph. Res. Lett., 35, L02813, https://doi.org/10.1029/2007GL032243.

Piepmeier, J. R., and Coauthors, 2017: SMAP L-band microwave radiometer: Instrument design and first year on orbit. IEEE Trans. Geosci. Remote Sens., 55, 1954-1966, https://doi.org/ 10.1109/TGRS.2016.2631978

Rondinelli, W. J., and Coauthors, 2015: Different rates of soil drying after rainfall are observed by the SMOS satellite and the South Fork in situ soil moisture network. J. Hydrometeor., 16, 889-903, https://doi.org/10.1175/JHM-D-14-0137.1.

Shellito, P. J., and Coauthors, 2016: SMAP soil moisture drying more rapid than observed in situ following rainfall events. Geophys. Res. Lett., 43, 8068-8075, https://doi.org/10.1002/2016GL069946.

Smith, A. B., and Coauthors, 2012: The Murrumbidgee soil moisture monitoring network data set. Water Resour. Res., 48 , W07701, https://doi.org/10.1029/2012WR011976.

Starks, P. J., J. L. Steiner, and A. J. Stern, 2014: Upper Washita River experimental watersheds: Land cover data sets (1974-2007) for two southwestern Oklahoma agricultural watersheds. J. Environ. Qual., 43, 1310-1318, https://doi.org/ 10.2134/jeq2013.07.0292.

Tetlock, E., B. Toth, A. Berg, T. Rowlandson, and J. T. Ambadan, 2019: An 11-year (2007-2017) soil moisture and precipitation dataset from the Kenaston Network in the Brightwater Creek basin, Saskatchewan, Canada. Earth Syst. Sci. Data, 11, 787-796, https://doi.org/10.5194/essd-11-787-2019. 